\title{
PLATELET-RICH PLASMA IN ARTHROSCOPIC REPAIRS OF COMPLETE TEARS OF THE ROTATOR CUFF
}

Eduardo Angeli Malavolta', Mauro Emilio Conforto Gracitelli', Edwin Eiji Sunada ${ }^{2}$, Eduardo Benegas ${ }^{3}$, Flavia de Santis Prada ${ }^{3}$, Raul Bolliger Neto ${ }^{3}$, Marcelo Bordalo Rodrigues ${ }^{4}$, Arnaldo Amado Ferreira Neto ${ }^{5}$, Olavo Pires de Camargo ${ }^{6}$

\section{ABSTRACT}

Objective: To evaluate shoulder functional results and the retear rate of arthroscopic repair of the rotator cuff augmented with platelet-rich plasma (PRP).Methods: Prospective case series with single-row arthroscopic repair of the rotator cuff augmented with PRP. Only cases of isolated supraspinatus tears with retraction of less than $3 \mathrm{~cm}$ were included in this series. The PRP used was obtained by apheresis. It was applied on liquid consistency in its activated form, with the addition of autologous thrombin. Patients were evaluated after 12 months of the surgical procedure. The Constant-Murley, UCLA and VAS scales were used, and the retear rate was assessed using magnetic resonance imaging (MRI). Results: Fourteen patients were evaluated (14 shoulders). The mean Constant-Murley score was $45.64 \pm 12.29$ before the operation and evolved to $80.78 \pm 13.22$ after the operation $(\mathrm{p}<0.001)$. The UCLA score increased from $13.78 \pm 5.66$ to $31.43 \pm 3.9(\mathrm{p}<0.001)$. The patients' pain level decreased from a median of $7.5(\mathrm{p} 25 \%=6, \mathrm{p} 75 \%=8)$ to $0.5(\mathrm{p} 25 \%=0$, $\mathrm{p} 75 \%=3)(\mathrm{p}=0.0013)$ according to the VAS score. None of the patients presented complete retear. Three patients (21.4\%) showed partial retear, without transfixation. Only one patient developed complications (adhesive capsulitis). Conclusion: Patients submitted to arthroscopic rotator cuff repair augmented with PRP showed significant functional improvement and none of them had complete retearing.

Keywords - Rotator Cuff; Plaletet-Rich Plasma, Arthroscopy

\section{INTRODUCTION}

Tears of the rotator cuff have a high prevalence in the general population ${ }^{(1)}$. Despite satisfactory clinical results with arthroscopic repair of the rotator cuff (arthroRRC) $)^{(2-4)}$, the index of rerupture is high, ranging from 10 to $95 \%{ }^{(2-6)}$.

Deficient healing between the tendon and bone is believed to be the main cause of reruptures. Biological strategies that improve the process of healing between tendon and bone in rotator cuff repair (RCR) are currently being sought ${ }^{(7-10)}$, with emphasis on the action of growth factors (GF). The platelet-rich plasma (PRP) is a fraction of plasma with platelet concentrations above baseline levels obtained autologously ${ }^{(11)}$, and rich in GF that are important during the healing process $^{(12)}$.

In orthopedics, the effects of PRP on the knee $\mathrm{e}^{(13,14)}$, in the spinal column ${ }^{(15)}$, in elbow tendinopathy ${ }^{(16)}$, and Achilles tendon lesions ${ }^{(17,18)}$ have been studied, with conflicting results. Few studies have evaluated the effect of PRP as an adjuvant to the healing of the rotator cuff $(\mathrm{RC})^{(19-24)}$, two of which were prospective and randomized ${ }^{(21,22)}$ and two of which were prospective cohort studies ${ }^{(23,24)}$. Two studies did not show any difference between groups ${ }^{(21,23)}$. However, a lower index of rerupture ${ }^{(24)}$ and better functional results ${ }^{(22)}$ have been evidenced with the use of PRP. The PRP

1 - Assistant Physician, Shoulder and Elbow Group, and Trauma Group, Institute of Orthopedics and Traumatology, USP School of Medicine, São Paulo, SP, Brazil.

2 - Collaborating Orthopedist, Shoulder and Elbow Group, Institute of Orthopedics and Traumatology, USP School of Medicine, São Paulo, SP, Brazil.



4 - Chief Physician, Department of Radiology, Institute of Orthopedics and Traumatology, USP School of Medicine, São Paulo, SP, Brazil.

5 - Doctor's degree in Medicine; Head, Shoulder and Elbow Group, Institute of Orthopedics and Traumatology, USP School of Medicine, São Paulo, SP, Brazil.

6 - Full Professor, Department of Orthopedics and Traumatology, USP School of Medicine, São Paulo, SP, Brazil.

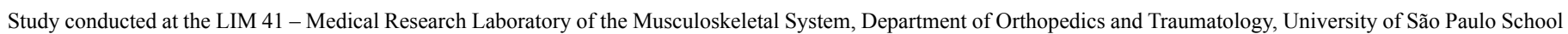
of Medicine.

Correspondence: Rua Dr. Ovídio Pires de Campos, 333 - Cerqueira César - 05403-010, São Paulo, SP. Email: eduardomalavolta@hotmail.com

Received for publication: 11/15/2011, accepted for publication: 2/7/2012.

The authors declare that there was no conflict of interest in conducting this work 
preparation and application methodology has also been controversial $^{(25)}$, and none of the previously published studies evaluated the efficacy of the compound obtained by apheresis and applied in its activated form, with the addition of thrombin. The objective of this study is to evaluate the functional results and the index of rerupture for arthroRRC with the use of PRP, and to describe the technique for its preparation and application.

\section{MATERIALS AND METHODS}

We conducted a prospective case series evaluating the result of arthroRRC combined with the use of PRP in patients with an isolated rupture of the supraspinatus tendon with less than $3 \mathrm{~cm}$ of retraction. The research protocol was approved by the ethics committee of the institution, and all patients signed an informed consent form. The procedures were performed by the same surgeon and at the same institution (IOT-HCFMUSP) during the period of September 2008 to March 2011.

\section{Selection of subjects}

The inclusion criteria were complete rupture of the supraspinatus tendon with less than $3 \mathrm{~cm}$ retraction and lack of rupture of the subscapularis and infraspinatus, confirmed by preoperative magnetic resonance imaging (preMRI); failure of conservative therapy performed for at least three months; fatty degeneration of RC muscle lower than Goutallier grade 2; absence of glenohumeral osteoarthritis or rotator cuff arthropathy; platelet concentration greater than or equal to $150,000 / \mathrm{mm}^{3}$; absence of coagulopathy or chronic use of anticoagulants; skeletally mature, with no age limits; absence of psychiatric disorders, fibromyalgia, painful cervical spine disorders, uncompensated clinical comorbidities, active or recent infection; absence of fractures or previous surgery in the affected shoulder.

The exclusion criteria were intraoperative observation of rupture of the tendon of the subscapularis or infraspinatus requiring repair, or supraspinatus tears with retraction greater than $3 \mathrm{~cm}$; lesions not amenable to complete repair; patients who did not undergo postoperative clinical evaluations.

\section{PRP Collection}

A Haemonetics MCS $+9000^{\circledR}$ cell separator and a 994-CFE apheresis-specific set (Haemonetics Corp.,
MA, USA) were used to prepare the PRP (Figure 1). Approximately $400 \mathrm{~mL}$ of blood were drained to a device for separation under 5800RPM continuous centrifugation for 15 minutes through a peripheral access. Sodium citrate was used as an anticoagulant at a ratio of $1 \mathrm{ml}$ for every $9 \mathrm{ml}$ of blood. In this device, after the separation of blood components by density gradient, an optical analyzer identified the platelet layer by its refraction characteristics and separated it into a sterile collection bag, obtaining about $30 \mathrm{ml}$ of PRP. The remaining blood was returned to the patient by the same venous access, resulting in no loss of the other blood components.

Ten milliliters of PRP plus $400 \mathrm{~mm}^{3}$ of $10 \%$ calcium chloride were used for the formation of thrombin from an autologous source, which was used with the activator of the coagulation cascade. After gel formed in the sample, the supernatant, which was rich in thrombin, was collected.

The material necessary for the subsequent application of PRP in its activated form was packaged in syringes: two aliquots of PRP (10 mL each) and two fractions of thrombin and $10 \%$ calcium chloride $(1.5$ and $0.8 \mathrm{~mL}$ each, respectively) (Figure 2). The entire collection procedure was performed after anesthesia.

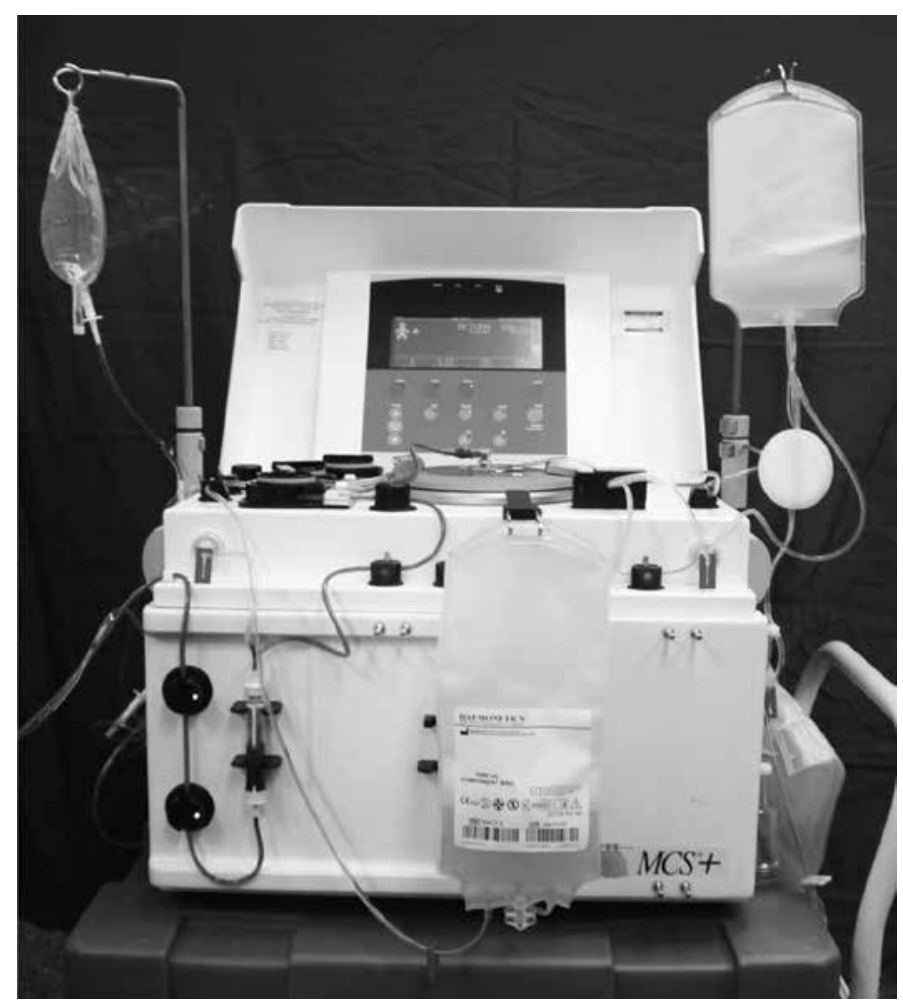

Figure 1 - Haemonetics MCS+ $9000^{\circledR}$ cell separator and 994-CFE apheresis-specific set (Haemonetics Corp., MA, USA). 


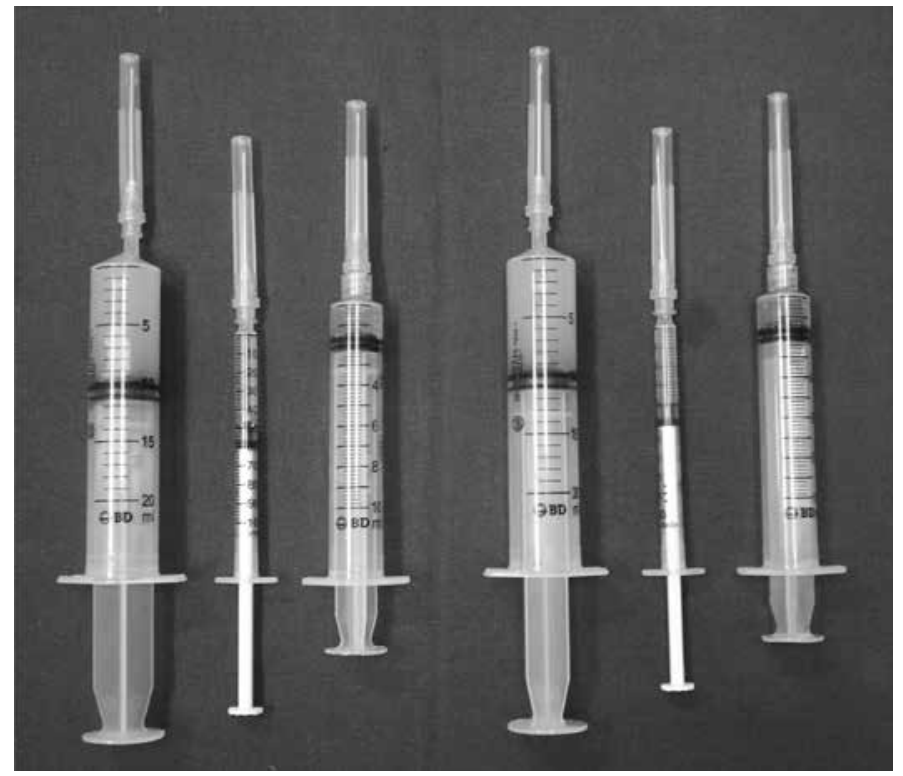

Figure 2 - PRP and platelet activators (calcium chloride and thrombin).

\section{Rotator cuff repair}

The patients were operated in the beach chair position under general anesthesia combined with an interscalene block. Bursectomy, acromioplasty, and coracoacromial ligament release were performed in all cases, as well as cruentation of the greater tubercle. No patient underwent resection of the distal clavicle.

The tendon of the long head of the biceps was approached through tenodesis when it presented instability, partial lesions larger than $50 \%$ or insertional lesions (SLAP lesions) types 3 and 4 . Tenodesis was performed using one of the more anterior ends of the anchor wire used in RCR through a single stitch fixing the supraspinatus tendon together with the long head of the biceps. The RC was repaired with 5 -mm bioabsorbable anchors doubly loaded with high strength wires. Tendon-tendon sutures were performed when necessary.

\section{Application of PRP}

The technique for applying the PRP was based on a study by Randelli et $\mathrm{al}^{(20)}$. Upon completion of the RCR, suture of the arthroscopic portals was performed except the posterior portal, which was maintained for visualization. A number 14 long needle was then introduced through the skin, and not by one of the previously created portals. The position of needle insertion was located at a point between the anterior and the lateral portals (Figure 3). The needle tip was then positioned in the tendon and bone

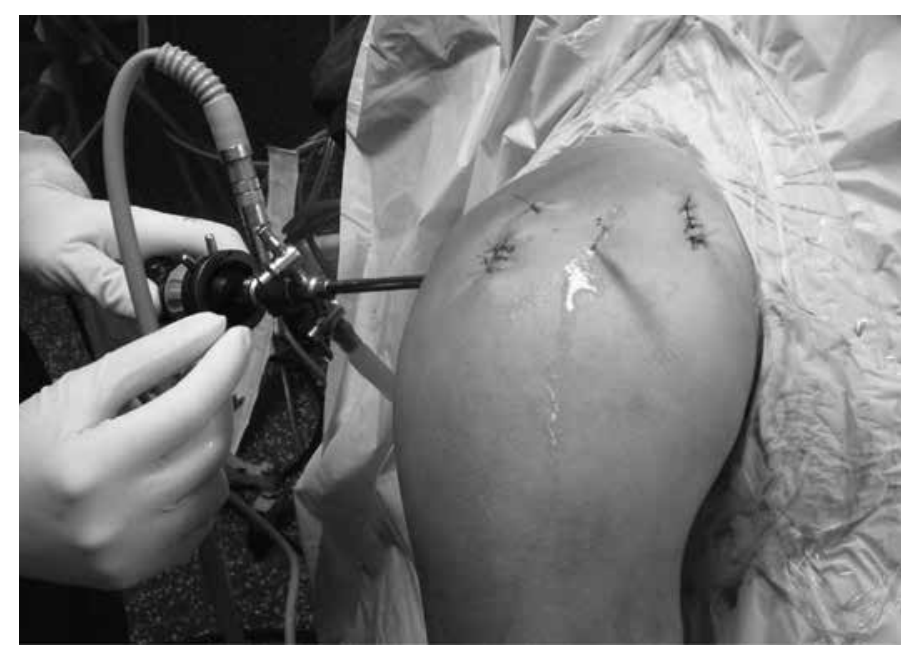

Figure 3 - Needle inserted through the skin, after portals are sutured.

interface (Figure 4). The saline infusion was then closed and the remaining liquid in the subacromial space was aspirated, while maintaining visualization. The platelet concentrate was then applied. Each $10 \mathrm{ml}$ of PRP collected was mixed with $1.5 \mathrm{ml}$ of autologous thrombin and $0.8 \mathrm{ml}$ of $10 \%$ calcium chloride and injected in liquid form through the previously placed needle. During this phase, an assistant obstructed the already sutured portals with their fingers to minimize leakage of the injected material (Figure 5). Five minutes after the application, the assistant ceased to block the portals and the posterior portal was sutured in the same way as the others.



Figure 4 - Needle positioned between the repaired tendon and the bone bed. 


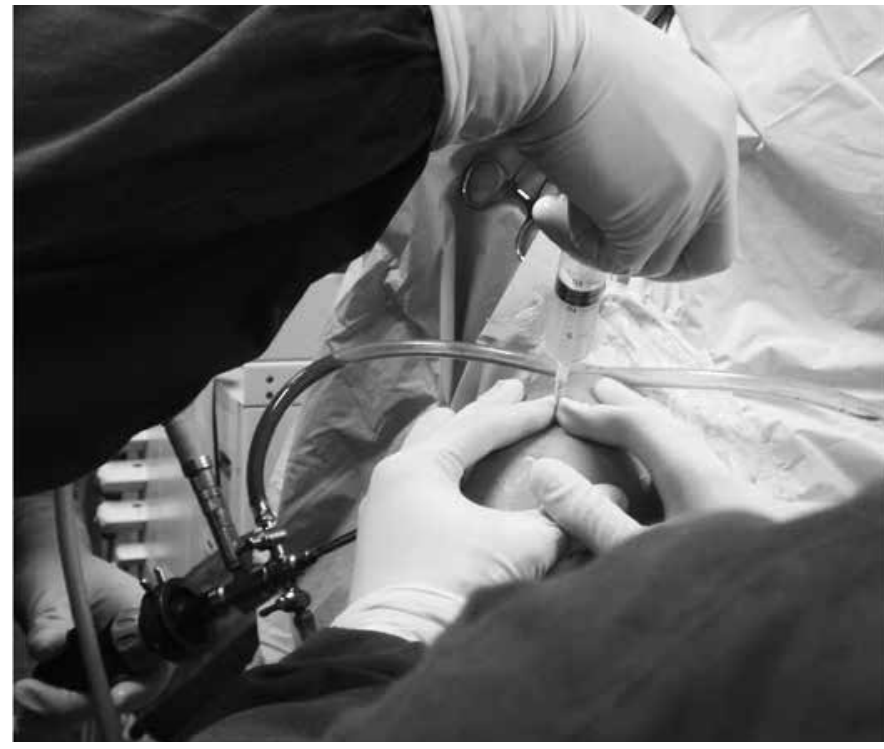

Figure $\mathbf{5}$ - Assistant manually blocking the already sutured portals while the PRP is injected.

\section{Postoperative care}

Immobilization with mesh Velpeau was maintained for a total of six weeks, and in the first three weeks no movements were performed with the shoulder. Slight movements with the elbow, wrist and fingers were directed. Light passive exercises were initiated after the end of the third week. Free active and activeassisted exercises were started only after the sixth week, with the termination of the use of the sling. Muscle strengthening (resistance active exercises) was performed only after significant movement gain in the $12^{\text {th }}$ week.

\section{VARIABLES ANALYZED}

\section{Clinical evaluation}

We performed a clinical assessment of patients through the Constant-Murley and UCLA functional scales, performed preoperatively and 12 months postoperatively. The pain visual analog scale (VAS) was measured in the same periods. Postoperative complications were also evaluated. The evaluations were performed by a physiotherapist from the Shoulder and Elbow Group of our institution, which did not participate in the study.

\section{Imaging evaluation}

The shape of the acromion (flat, curved or hooked) was evaluated in preoperative radiographs in the supraspinatus tendon tunnel view. The size of the supra- spinatus tendon lesion was measured in $\mathrm{mm}$ on the preMRI. On the postoperative magnetic resonance imaging (postMRI) held at 12 months of follow-up, whether the RC was intact (complete restoration of its insertion), with partial rerupture (thinning of insertion, but without transfixing lesion) or complete rerupture (transfixing lesion) was investigated. Magnetic resonance imaging (MRI) was evaluated by a radiologist specialized in musculoskeletal imaging.

\section{Intraoperative assessment}

Data on the pattern of the lesion $(\mathrm{C}, \mathrm{V}$, or $\mathrm{L})$, the number of sutures and anchors used, the appearance of the subscapularis tendon (normal or partial rupture), and whether or not tenodesis was performed were collected.

\section{Statistical analysis}

Data normality was tested by the Shapiro-Wilk test. The variables were evaluated using the Student's t-test (parametric data) or the Wilcoxon test (nonparametric data). Parametric data were expressed as means and standard deviations; nonparametric data as medians and percentiles. Categorical data were put forth as percentages. The value of $p<0.05$ was considered statistically significant. We used Stata 10.0.

\section{RESULTS}

During the study period, 15 patients underwent the procedure ( 15 shoulders). Of these, one was excluded because the patient evolved with ipsilateral hemiparesis to the shoulder surgery after resection of a brain meningioma. Fourteen patients (14 shoulders), eight of whom were females $(57.14 \%)$, were evaluated. The right side was affected in $11(78.6 \%)$. All the cases occurred on the dominant side. The mean age was $51.86 \pm 8.72$ years.

The pain of the patients showed significant improvement according to the VAS $(p=0.0013)$, decreasing from a median of $7.5(\mathrm{p} 25 \%=6, \mathrm{p} 75 \%$ $=8)$ to $0.5(\mathrm{p} 25 \%=0, \mathrm{p} 75 \%=3)$. The comparison between pre- and post-surgical scores on the ConstantMurley and UCLA scales can be seen in Table 1. Only one patient developed clinical complication (adhesive capsulitis). There were no cases of infection or allergic reaction.

A curved acromion occurred in 11 patients (78.6\%). Hooked and flat acromions were observed in two 
(14.3\%) patients and one (7.1\%) patient, respectively.

Regarding the pattern of injury, five $(35.7 \%)$ were "C", five (35.7\%) were "L", and four (28.6\%) were "V". The subscapularis tendon was intact in 12 $(85.7 \%)$. In the other two cases, there was a partial joint injury that did not require repair. Tenodesis of the long head of the biceps was performed in two patients $(14.3 \%)$. In the other cases the biceps was intact.

An anchor was used in 10 patients (71.4\%), and two anchors were used in four $(28.6 \%)$. Two patients $(14.3 \%)$ received additional tendon-tendon sutures. Most patients (nine cases) had their lesions repaired with two stitches $(64.3 \%)$. Three sutures were required in one $(7.1 \%)$, four sutures in three $(21.4 \%)$ and six sutures in one $(7.1 \%)$ patient.

The lesions were $12.5 \pm 4.11 \mathrm{~mm}$ in length and had $15.64 \pm 7.26 \mathrm{~mm}$ retraction, according to the preMRI.

In the postMRI, no patient had complete supraspinatus tendon rerupture. The tendon was presented intact in 11 cases $(78.6 \%)$ (Figure 6). Partial rerupture was observed in three patients (21.4\%) (Figure 7); in two cases it affected about $50 \%$ of the thickness of the tendon, and $25 \%$ in one case. All reruptures affected the joint surface of the supraspinatus.

Table 1 - Pre- and postoperative values of the functional scales.

\begin{tabular}{c|c|c|c|c|c}
\hline & \multicolumn{2}{|c|}{ Preoperative } & \multicolumn{2}{c|}{ Postoperative } & \\
\hline & Mean & SD & Mean & SD & p \\
\hline Constant-Murley & 45.64 & 12.29 & 80.78 & 13.22 & $<0.0001$ \\
\hline UCLA & 13.78 & 5.66 & 31.43 & 3.9 & $<0.0001$ \\
\hline
\end{tabular}

\section{DISCUSSION}

The clinical results of this study show a significant improvement when comparing the pre- to the postoperative evaluations, similar to other publications ${ }^{(2-4)}$. Among the comparative studies evaluating the use of PRP in arthroRRC, three did not observe any clinical difference between the groups ${ }^{(21,23,24)}$. Randelli et al. ${ }^{(22)}$, however, note less pain in the first month and better evaluations according to the Constant-Murley scale at the end of the third month in cases that used PRP in their report. Evaluating a subgroup of patients with small- and medium-sized tears, they observed that those with the addition of PRP performed better in all functional scales at the end of the first quarter, and significantly better values for the Constant-
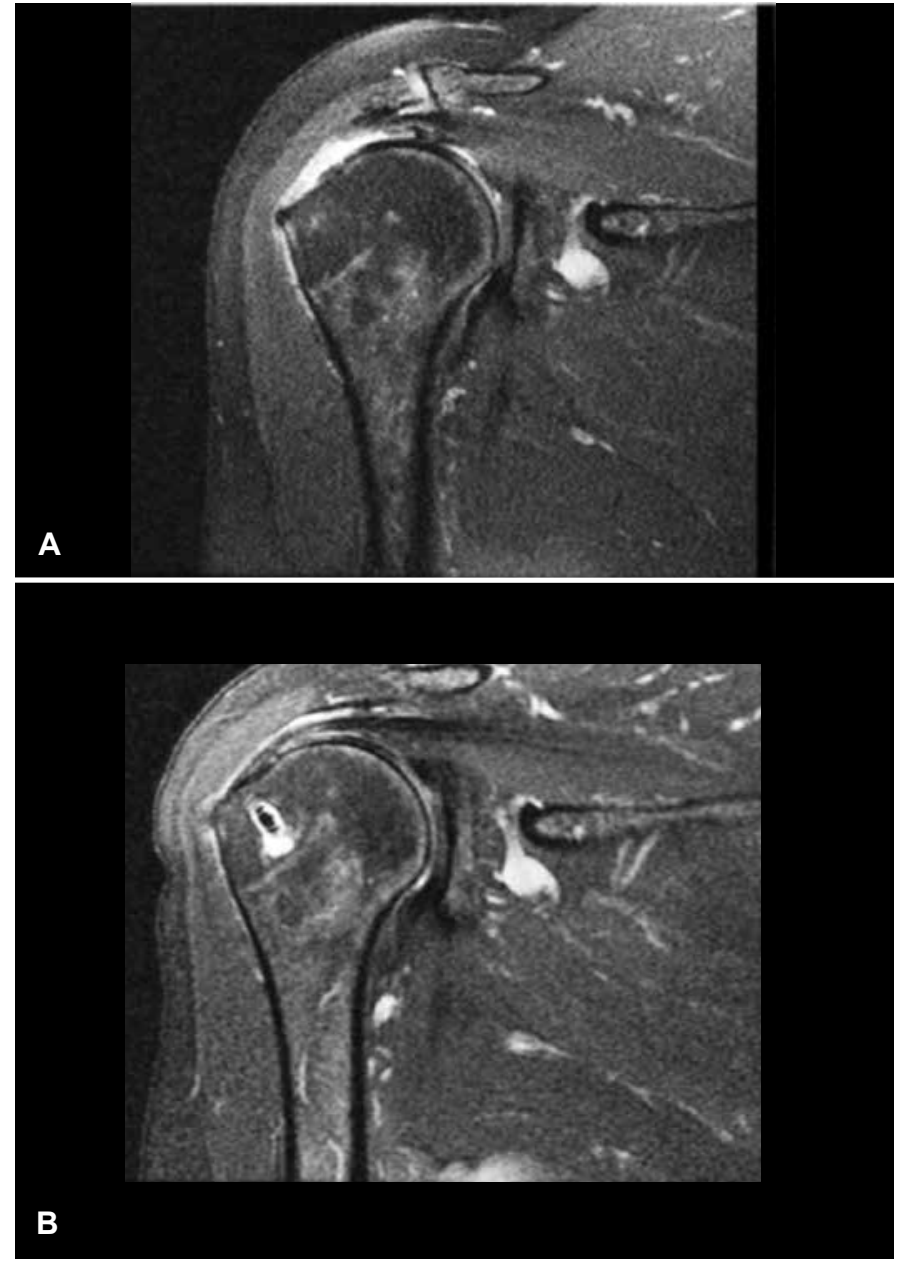

Figure 6 - MR image. (A) Preoperatively, with complete rupture of the supraspinatus. (B) Postoperatively, with no evidence of rerupture (interposition of fluid between the tendon and bone is not observed).

Murley scale at 12 months and external rotational strength at three, six, 12 and 24 months.

With respect to structural integrity, we observed that all the comparative studies on the effect of PRP in arthroRRC ${ }^{(21-24)}$ demonstrated a lower incidence of rerupture with the use of platelet concentrate. However, only Barber et al $^{(24)}$ observed a statistically significant difference between groups. Evaluating only isolated ruptures of the supraspinatus smaller than $3 \mathrm{~cm}$, Castricini et $\mathrm{al}^{(21)}$ found only one rerupture in 40 patients $(2.5 \%)$. Randelli et al. ${ }^{(22)}$ analyzed a subgroup of patients with small and medium-sized tears, and observed reruptures in $14 \%$ of patients. With a less homogeneous sample, including extensive ruptures, Jo et $\mathrm{al}^{(23)}$ and Barber et $\mathrm{al}^{(24)}$ identified rerupture rates of 26.7 and $30 \%$, respectively. Our study did not show any complete reruptures, which was an inferior result to studies using $\mathrm{PRP}^{(21-24)}$ as well as those that did not use $\mathrm{PRP}^{(2-6)}$. It is worth noting that we performed the 

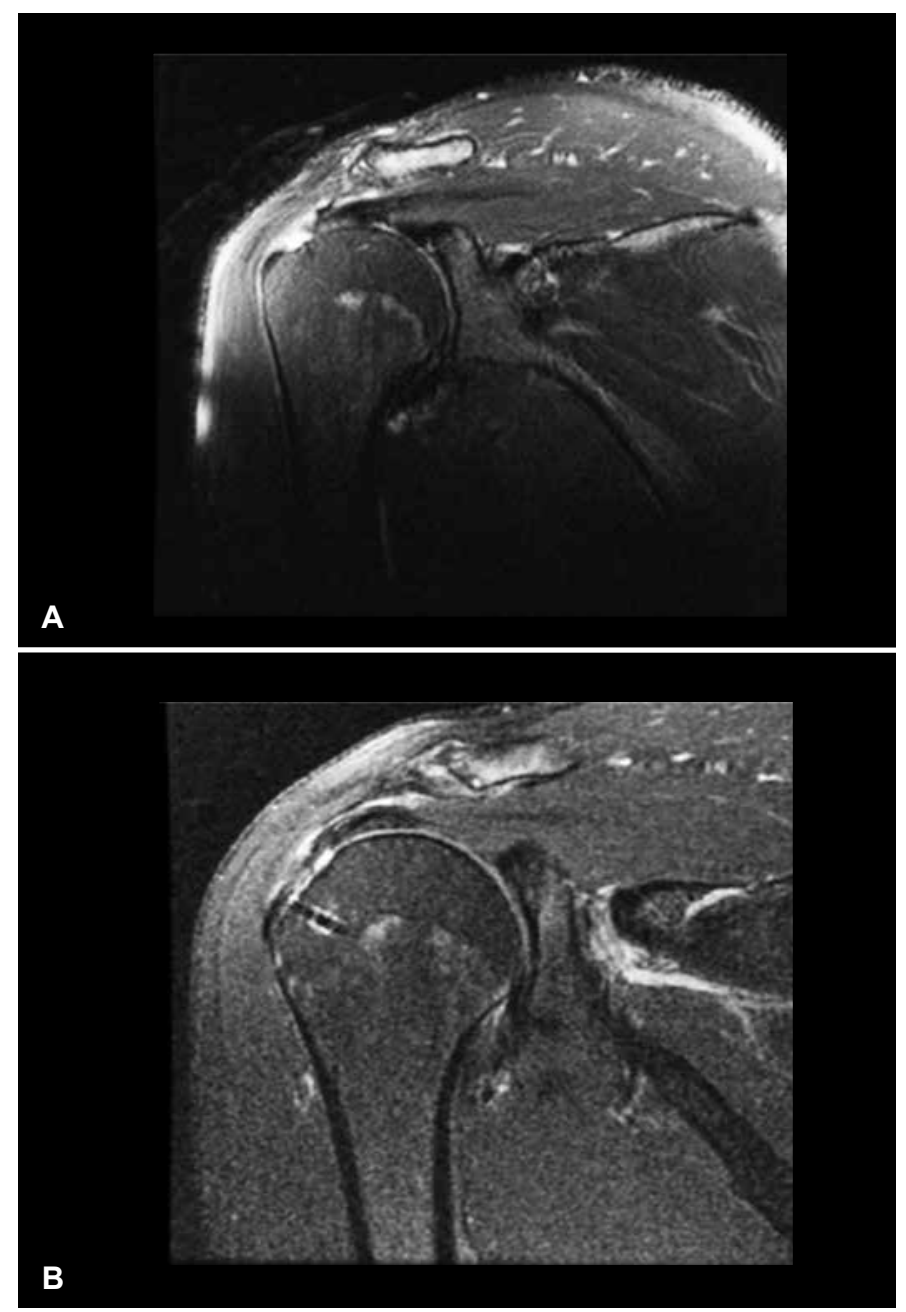

Figura 7 - Imagem de RM. (A) Pré-operatório, com rotura completa do supraespinal. (B) Pós-operatório, com sinais de rerrotura parcial articular (nota-se a interposição de líquido sinovial entre o tendão e o osso medialmente à âncora, sem descontinuidade do folheto bursal).

MRI at 12 months postoperatively, a time earlier than that of other publications ${ }^{(2,5,21,22)}$. Furthermore, we evaluated only isolated lesions of the supraspinatus with less than $3 \mathrm{~cm}$ retraction, unlike other authors, who have included large and extensive ruptures in their evaluations ${ }^{(2,4,5,23,24)}$.

There is great heterogeneity in the methods of obtaining PRP described in literature, and they are divided into two groups: apheresis ${ }^{(26)}$ and centrifugation $^{(27)}$. The apheresis method employed in this study presents higher platelet levels and lower leukocyte concentrations $^{(28)}$, as the PRP obtained in this manner is considered more pure ${ }^{(25)}$. Centrifugation, currently used by most companies, has the advantages of having a lower cost and requiring simpler materials ${ }^{(27)}$. Among the arthroRRC studies, only Jo et al ${ }^{(23)}$ used PRP obtained by apheresis.

The manner of applying the PRP varies between studies. We used concentrated liquid form, as described by Randelli et al $^{(20)}$ and subsequently used by Randelli et $\mathrm{al}^{(22)}$ in their clinical trial. Other authors, however, use the PRP in gel form, and push it along the anchor wires prior to suturing ${ }^{(21,23,24)}$. We believe that this method can lead to loss of GF and parts of the clot, as it is performed with saline infusion, unlike the form used by us, in which the application is performed after closing the infusion, at the end of the procedure. Among the advantages of the application in a solid consistency, we can cite the fact that the PRP can conceivably be placed effectively between the tendon and bone, unlike what occurs with the liquid consistency, in which the PRP spreads through the subacromial space, even when positioning the needle at the tendon-bone interface.

Another source of confusion and heterogeneity between the studies is the application of concentrate that is activated or not. In our study, we use the PRP that has been activated by the addition of thrombin and calcium chloride. Mazzucco et $\mathrm{al}^{(29)}$ and Han et $\mathrm{al}^{(30)}$ describe that the activation of PRP with thrombin leads to an immediate release of GF, and that a slower and more prolonged release could increase the beneficial effects of PRP. Moreover, Virchenko et $\mathrm{al}^{(31)}$ show that the use of thrombin increases the effectiveness of PRP in tendon repair. Only two studies ${ }^{(20,22)}$ have used thrombin, and the other authors have applied nonactivated $\operatorname{PRP}^{(21,23,24)}$. Our study is unique in that it evaluates the use of PRP in arthroRRC using material obtained by apheresis and applied with the addition of thrombin.

A Haemonetics MCS $+9000^{\circledR}$ cell separator and a 994-CFE apheresis-specific set (Haemonetics Corp., MA, USA) were used to prepare the PRP. This same method was used in two other studies performed at our institution ${ }^{(13,14)}$, and has proven to be effective in obtaining high platelet concentrations. O'Neil ${ }^{(32)}$ and de Almeida et $\mathrm{al}^{(14)}$ observed an average concentration of $1,420,000$ and $1,185,166$ platelets $/ \mathrm{mm}^{3}$, respectively. Thus, we chose not to measure the number of platelets in our study.

We can cite the small sample, clinical follow-up of only 12 months, and a non-comparative design as the main limitations of the study. A prospective randomized clinical trial is currently being conducted at our institution, with which we hope to get more consistent answers about the real effectiveness 
of the method. Clinical and MRI evaluation in all patients at the end of the follow-up time conducted in a standardized way are favorable points, besides addressing a homogeneous sample, with strict inclusion criteria.

\section{REFERENCES}

1. Yamamoto A, Takagishi K, Osawa T, Yanagawa T, Nakajima D, Shitara H, et al. Prevalence and risk factors of a rotator cuff tear in the general population. J Shoulder Elbow Surg. 2010;19(1):116-20.

2. Cole BJ, McCarty LP, Kang RW, Alford W, Lewis PB, Hayden JK. Arthroscopic rotator cuff repair: prospective functional outcome and repair integrity at minimum 2-year follow-up. J Shoulder Elbow Surg. 2007;16(5):579-85.

3. Burks RT, Crim J, Brown N, Fink B, Greis PE. A prospective randomized clinical trial comparing arthroscopic single- and double-row rotator cuff repair: magnetic resonance imaging and early clinical evaluation. Am J Sports Med. 2009;37(4):674-82.

4. Lafosse L, Brozska R, Toussaint B, Gobezie R. The outcome and structural integrity of arthroscopic rotator cuff repair with use of the double-row suture anchor technique. J Bone Joint Surg Am. 2007;89(7):1533-41.

5. Galatz LM, Ball CM, Teefey SA, Middleton WD, Yamaguchi K. The outcome and repair integrity of completely arthroscopically repaired large and massive rotator cuff tears. J Bone Joint Surg Am. 2004;86(2):219-24.

6. Frank JB, EIAttrache NS, Dines JS, Blackburn A, Crues J, Tibone JE. Repair site integrity after arthroscopic transosseous-equivalent suture-bridge rotator cuff repair. Am J Sports Med. 2008;36(8):1496-503.

7. Dines JS, Grande DA, Dines DM. Tissue engineering and rotator cuff tendon healing. J Shoulder Elbow Surg. 2007;16(Suppl 5):S204-7.

8. Cheung EV, Luz Silverio BA, Sperling JW. Strategies in biologic augmentation of rotator cuff repair: a review. Clin Orthop Relat Res. 2010;468(6):1476-84.

9. Edwards SL, Lynch TS, Saltzman MD, Terry MA, Nuber GW. Biologic and Pharmacologic augmentation of rotator cuff repairs. J Am Acad Orthop Surg. 2011;19(10):583-9.

10. Hogan MV, Bagayoko N, James R, Starnes T, Katz A, Chhabra AB. Tissue engineering solutions for tendon repair. J Am Acad Orthop Surg. 2011;19(3):134-42.

11. Marx RE. Platelet-rich plasma (PRP): what is PRP and what is not PRP? Implant Dentistry. 2001;10(4):225-8.

12. Gamradt SC, Rodeo SA, Warren RF. Platelet rich plasma in rotator cuff repair. Tech Orthop. 2007;22(1):26-33.

13. D'Elia CO, Rezende MU, Bitar AC, Tatsui N, Pecora JR, Hernandez AJ, et al. Comparison between platelet-rich plasma and autologous iliac grafts for tibial osteotomy. Cartilage. 2010;1(4):320-7.

14. de Almeida AM, Demange MK, Sobrado MF, Bordalo MR, Pedrinelli A, Hernandez AJ. Patellar tendon healing with platelet-rich plasma: a prospective randomized controlled trial. Am J Sports Med. 2012;40(6):1282-8.

15. Carreon LY, Glassman SD, Anekstein Y, Puno RM. Platelet gel (AGF) fails to increase fusion rates in instrumented posterolateral fusions. Spine. 2005;30(9):E243-6.

16. Peerbooms JC, Sluimer J, Bruijn DJ, Gosens T. Positive effect of an autologous platelet concentrate in lateral epicondylitis in a double-blind randomized controlled trial: platelet-rich plasma versus corticosteroid injection with a 1-year follow-up. Am J Sports Med. 2010;38(2):255-62.

17. de Vos RJ, Weir A, van Schie HTM, Bierma-Zeinstra SMA, Verhaar JAN,

\section{CONCLUSION}

Patients undergoing arthroRRC associated with the use of PRP showed a significant functional improvement and no cases of complete rerupture.
Weinans $\mathrm{H}$, et al. Platelet-rich plasma injection for chronic Achilles tendinopathy: a randomized controlled trial. JAMA. 2010;303(2):144-9.

18. Schepull T, Kvist J, Norrman H, Trinks M, Berlin G, Aspenberg P. Autologous platelets have no effect on the healing of human achilles tendon ruptures: a randomized single-blind study. Am J Sports Med. 2010;39(1):38-47.

19. Maniscalco P, Gambera D, Lunati A, Vox G, Fossombroni V, Beretta R, et al. The "Cascade" membrane: a new PRP device for tendon ruptures. Description and case report on rotator cuff tendon. Acta Biomed. 2008;79(3):223-6.

20. Randelli PS, Arrigoni P, Cabitza P, Volpi P, Maffulli N. Autologous platelet rich plasma for arthroscopic rotator cuff repair. A pilot study. Disabil Rehabil. 2008;30(20-22):1584-9.

21. Castricini R, Longo UG, De Benedetto M, Panfoli N, Pirani P, Zini R, et al. Platelet-rich plasma augmentation for arthroscopic rotator cuff repair: a randomized controlled trial. Am J Sports Med. 2010 Dec;39:258-65.

22. Randelli P, Arrigoni P, Ragone V, Aliprandi A, Cabitza P. Platelet rich plasma in arthroscopic rotator cuff repair: a prospective RCT study, 2-year follow-up. J Shoulder Elbow Surg. 2011;20(4):518-28.

23. Jo $\mathrm{CH}$, Kim JE, Yoon KS, Lee JH, Kang SB, Lee JH, et al. Does platelet-rich plasma accelerate recovery after rotator cuff repair? A prospective cohort study. Am J Sports Med. 2011;39(10):2082-90.

24. Barber FA, Hrnack SA, Snyder SJ, Hapa O. Rotator cuff repair healing influenced by platelet-rich plasma construct augmentation. Arthroscopy. 2011;27(8):1029-35.

25. Ehrenfest DMD, Rasmusson L, Albrektsson T. Classification of platelet concentrates: from pure platelet-rich plasma (P-PRP) to leucocyte- and platelet-rich fibrin (L-PRF). Trends Biotechnol. 2009;27(3):158-67.

26. Whitman H, Berry L, Green DM. Platelet Gel: An autologous alternative to fibrin glue with applications in oral and maxillofacial surgery. J Oral Maxillofac Surg. 1997;55(11):1294-9.

27. Landesberg R, Roy M, Glickman RS. Quantification of growth factor levels using a simplified method of platelet-rich plasma gel preparation. J Oral Maxillofac Surg. 2000;58(3):297-300.

28. Weibrich G, Kleis WK, Hafner G, Hitzler WE, Wagner W. Comparison of platelet, leukocyte, and growth factor levels in point-of-care platelet-enriched plasma, prepared using a modified Curasan kit, with preparations received from a local blood. Clin Oral Impl Res. 2003;14(3):357-62.

29. Mazzucco L, Balbo V, Cattana E, Borzini P. Platelet-rich plasma and platelet gel preparation using Plateltex. Vox Sang. 2008;94(3):202-8.

30. Han B, Woodell-May J, Ponticiello M, Yang Z, Nimni M. The effect of thrombin activation of platelet-rich plasma on demineralized bone matrix osteoinductivity. J Bone Joint Surg Am. 2009;91(6):1459-70.

31. Virchenko $O$, Grenegård $M$, Aspenberg $P$. Independent and additive stimulation of tendon repair by thrombin and platelets. Acta Orthop. 2006;77(6):960-6.

32. O'Neill EM, Zalewski WM, Eaton LJ, Popovsky MA, Pivacek LE, Ragno G, et al. Autologous platelet-rich plasma isolated using the Haemonetics Cell Saver 5 and Haemonetics MCS+ for the preparation of platelet gel. Vox Sang. 2001;81(3):172-5. 